catalytically active, but the non-hindered tetraphenyl species is inactive.

As noted above, the intermediate active species is ESR-silent. This seems to indicate a diamagnetic ruthenium-oxo species (for example, $\mathrm{Ru}^{\mathrm{IV}}=\mathrm{O}$ or $\mathrm{O}=\mathrm{Ru}^{\mathrm{VI}}=\mathrm{O}$ ) or a coupled paramagnetic species $\left(\mathrm{Ru}^{\mathrm{III}}-\mathrm{O}-\mathrm{O}-\mathrm{Ru}^{\mathrm{III}}\right)$ as the active intermediate. These conjectures are supported by our infrared spectra and by analogy with the porphyrin system ${ }^{1}$. A ruthenium(v) active species may be ruled out because an ESR-active intermediate is formed in the presence of periodate $^{13}$. As the $\left\{\left[\mathrm{WZnRu}_{2}^{\mathrm{III}}(\mathrm{OH})\left(\mathrm{H}_{2} \mathrm{O}\right)\right]\left(\mathrm{ZnW}_{9} \mathrm{O}_{34}\right)_{2}\right\}^{11-}$ compound is only catalytically active after a long induction period, we propose slow formation of a ruthenium(IV)-oxo species, followed by fast reaction under turnover conditions. We found that the induction period could be eliminated by the in situ reduction of the original $\mathrm{Ru}$ (III) compound to the $\mathrm{Ru}$ (II) analogue with two equivalents of zinc metal under argon (Fig. 2 inset). Addition of dioxygen immediately brought about adamantane hydroxylation at a rate slightly higher than the expected post-induction rate. We therefore propose that dioxygen activation, as shown in equation (2) below, occurs. This may or may not be followed by a disproportionation reaction, equation (3), as found in the ruthenium porphyrin system.

$$
\begin{aligned}
& \mathrm{Ru}^{\prime \prime}+\mathrm{O}_{2} \longrightarrow\left[\mathrm{Ru}^{\mathrm{III}}-\mathrm{O}-\mathrm{O}-\mathrm{Ru}^{\mathrm{III}}\right] \longrightarrow 2 \mathrm{Ru}^{\mathrm{IV}}=\mathrm{O} \\
& 2 \mathrm{Ru}^{\mathrm{IV}}=\mathrm{O} \longrightarrow \mathrm{Ru}+\mathrm{O}=\mathrm{Ru} \mathrm{vl}^{\mathrm{Vl}}=\mathrm{O}
\end{aligned}
$$

Any of the oxygen-containing intermediates shown could be the active species. We believe, however, that it is more likely that the active species is a $\mathrm{Ru}^{\mathrm{IV}}=\mathrm{O}$ intermediate, which has been shown to be active for epoxidation in sterically crowded ruthenium complexes ${ }^{14}$. Trans-ruthenium dioxo species, active in epoxidation, seem to be unlikely, given the crowded tetragonal coordination of ruthenium in the polyoxometalate in contrast to the advantageous square planar coordination of ruthenium in the porphyrin ${ }^{1}$. Conceivable cis-ruthenium dioxo species are also unlikely, as they have not been shown to promote epoxidation. ${ }^{15}$

Received 19 November 1996; accepted 28 May 1997.

1. Groves, J. T. \& Quinn, R. Aerobic epoxidation of olefins with ruthenium porphyrin catalysts. I. Am Chem. Soc. 107, 5790-5792 (1985).

2. Neumann, R. \& Khenkin, A. M. Noble metal $\left(\mathrm{Ru}^{\mathrm{III}}, \mathrm{Pd}^{\mathrm{II}}, \mathrm{Pt}^{\mathrm{II}}\right)$ substituted "sandwich" type polyoxometalates: preparation, characterization and catalytic activity in oxidations of alkanes and alkenes by peroxides. Inorg. Chem. 34, 5733-5760 (1995).

Hill, C. L. \& Prosser-McCartha Homogeneous catalysis by transition metal oxygen anion clusters. Coord. Chem. Rev. 143, 407-455 (1995).

4. Okuhara, T., Mizuno, N. \& Masons, M. Catalytic properties of heteropoly compounds. Adv. Catal. 41, 113-252 (1996)

5. Sheldon, R. A. \& Kochi, J. K. Metal Catalyzed Oxidations of Organic Compounds (Academic, New York, 1981).

6. Neumann, R., Khenkin, A. M. \& Dahan, M. Hydroxylation of alkanes with molecular oxygen catalysed by a new ruthenium substituted polyoxometalate, $\left[\mathrm{WZnRu}_{2}{ }^{\mathrm{III}}(\mathrm{OH})\left(\mathrm{H}_{2} \mathrm{O}\right)\left(\mathrm{ZnW}_{9} \mathrm{O}_{34}\right)_{2}\right]^{11-}$. Angew. Chem. Int. Edn. Engl. 34, 1587-1589 (1995).

. Sorokin, A., Robert, A. \& Meunier, B. Intermolecular kinetic isotope effect in alkane hydroxylation catalyzed by manganese and iron porphyrin complexes. J. Am. Chem. Soc. 115, 7293-7299 (1993).

8. Seok, W. K. \& Meyer, T. J. Multiple electron oxidation of phenols by an oxo-complex of ruthenium(IV). J. Am. Chem. Soc. 110, 7358-7367 (1988).

9. Collman, J. P. et al. A synthetic analogue for the oxygen binding site in cytochrome C oxidase. J. Am Chem. Soc. 1167, 9783-9784 (1994)

10. Paeng, I. R. \& Nakamoto, K. Resonance Raman spectra of reaction intermediates in the oxidation process of ruthenium(II) and iron(II) porphyrins. J. Am. Chem. Soc. 112, 3289-3297 (1990).

11. Neumann, R. \& Dahan, M. Transition metal substituted Keggin type polyoxomolybdates as bifunction catalysts for the epoxidation of alkenes by molecular oxygen. J. Chem. Soc. Chem. Commun. 171-172 (1995).

12. Randell, W. J., Weakley, T. J. R. \& Finke, R. G. Oxidation resistant inorganic porphyrin analog polyoxometalates. 3 . The synthesis and X-ray crystallographic characterization of a new heteropolyoxoanion structural type, the diruthenium-oxo-bridged "bimetallic unorganic-polyphyrin analog $\mathrm{KLi}_{15}\left[\mathrm{O}\left\{\mathrm{Ru}^{\mathrm{IV}} \mathrm{Cl}\left(\alpha_{2}-\mathrm{P}_{2} \mathrm{~W}_{17} \mathrm{O}_{61}\right)\right\}_{2}\right] \cdot 2 \mathrm{KCl} \cdot 60 \mathrm{H}_{2} \mathrm{O}$ ". Inorg. Chem. 32, 1068-1071 (1993).

13. Neumann, R. \& Abu-Gnim, C. Alkene oxidation catalysed by a ruthenium substituted heteropolyanion, $\mathrm{SiRu}\left(\mathrm{H}_{2} \mathrm{O}\right) \mathrm{W}_{11} \mathrm{O}_{39}$ : the mechanism of the periodate mediated oxidative cleavage. J. Am. Chem. Soc. 112, 6025-6031 (1990).

14. Bailey, C. \& Drago, R. S. catalytic epoxidation of alkenes by sterically crowded ruthenium complexes. J. Chem. Soc. Chem. Commun. 179-180 (1987).

15. Goldstein, A. A., Beer, R. H. \& Drago, R. S. Catalytic oxidation of hydrocarbons with $\mathrm{O}_{2}$ or $\mathrm{H}_{2} \mathrm{O}_{2}$ using a sterically hindered ruthenium complex. J. Am. Chem. Soc. 116, 2424-2429 (1994).

Acknowledgements. We thank A. Sorokin for the sample of 1,3-adamantane- $d_{2}$. This work was supported by the Basic Research Foundation administered by the Israel Academy of Sciences and Humanities.

\section{On/off blinking and switching behaviour of single molecules of green fluorescent protein}

\author{
Robert M. Dickson ${ }^{\star}$, Andrew B. Cubitt $\dagger$, Roger Y. Tsien $\ddagger$
} \& W. E. Moerner*

* Department of Chemistry and Biochemistry 0340, University of California San Diego, La Jolla, California 92093-0340, USA

$\dagger$ Aurora Biosciences, 11149 North Torrey Pines Road, La Jolla, California 92037, USA

$\ddagger$ Department of Pharmacology and Howard Hughes Medical Institute 0647,

University of California San Diego, La Jolla, California 92093-0647, USA

Optical studies of individual molecules at low and room temperature can provide information about the dynamics of local environments in solids, liquids and biological systems unobscured by ensemble averaging ${ }^{1-14}$. Here we present a study of the photophysical behaviour of single molecules of the green fluorescent protein (GFP) derived from the jellyfish Aequorea victoria. Wildtype GFP and its mutant have attracted interest as fluorescent biological labels because the fluorophore may be formed in $v v^{15,16}$. GFP mutants immobilized in aereated aqueous polymer gels and excited by 488-nm light undergo repeated cycles of fluorescent emission ('blinking') on a timescale of several seconds-behaviour that would be unobservable in bulk studies. Eventually the individual GFP molecules reach a long-lasting dark state, from which they can be switched back to the original emissive state by irradiation at $405 \mathrm{~nm}$. This suggests the possibility of using these GFPs as fluorescent markers for timedependent cell processes, and as molecular photonic switches or optical storage elements, addressable on the single-molecule level.

Wild-type GFP has two absorption maxima-a strong peak at $396 \mathrm{~nm}$, and a weak one at $476 \mathrm{~nm}$ (ref. 15) — but only one emission peak at $508 \mathrm{~nm}$, indicating that excited-state relaxation to a common emissive level occurs. The absorption peaks correspond to the neutral and anionic chromophore states, respectively, which can be interconverted by an excited-state proton transfer and spontaneous ground-state processes ${ }^{16-18}$. Ser 65 (serine, S) and Thr 203 (threonine, T) are particularly close to the chromophore ${ }^{19,20}$ and strongly influence its photophysical properties. Alteration of Ser 65 strongly favours the anionic form (which has a long-wavelength absorption), producing mutants which can easily be pumped with readily available green lasers ${ }^{16,19,20}$. Aromatic residues phenylalanine (F) and tyrosine (Y) at position 203 further increase the peak excitation wavelength by $13-24 \mathrm{~nm}$, probably by increasing the polarizability around the chromophore through $\pi-\pi$ interactions $^{19}$. Because of the higher brightness compared to wild type, we focus here on two particular yellow-fluorescing GFP mutants, S65G/S72A/T203F (denoted T203F) and S65G/ S72A/T203Y (denoted T203Y), which differ only by the presence of a hydroxyl group.

These mutants' long-wavelength absorption and emission properties (Fig. 1) enable facile excitation with an argon-ion laser, while allowing high-efficiency fluorescence collection and background rejection. In the bulk, T203F (Fig. 1a) has a dominant absorption at $510 \mathrm{~nm}$, and a weak peak near $405 \mathrm{~nm}$. Excitation at $488 \mathrm{~nm}$ produces long-wavelength emission, whereas excitation at $400 \mathrm{~nm}$ gives emission predominantly peaking at $455 \mathrm{~nm}$ rather than $525 \mathrm{~nm}$ (Fig. 1a inset). By analogy to previously studied mutants, the long-wavelength absorption and emission probably correspond to the anionic form, and the short-wavelength absorption probably arises from a small fraction of molecules with neutral chromophores $^{16,17}$. In contrast to T203F, T203Y (Fig. 1b) shows 
much weaker absorption at $400 \mathrm{~nm}$ which produces (Fig. 1b inset) only weak emission at $470 \mathrm{~nm}$ and dominant long-wavelength fluorescence $(535 \mathrm{~nm})$. Excitation at $488 \mathrm{~nm}$, however, yields emission nearly identical to that of T203F. The Ser 65 and Thr 203 mutations combine to make the low-energy absorption strongest in both mutants (opposite to wild-type photophysics); however, the emission properties suggest that a larger portion of the neutral form persists in T203F.

Single molecules of T203F (number of molecules, $n=178$ ) and T203Y $(n=199)$ immobilized in polyacrylamide gels ${ }^{21}$ were directly imaged by excitation at $488 \mathrm{~nm}$ and detection of polarization-dependent emission. During several minutes of illumination, each molecule produced several seconds of fluorescence, then several seconds without emission, followed by resumption of emission, repeating over the course of many minutes. Such highcontrast 'blinking' behaviour, which is unobservable in bulk experi-
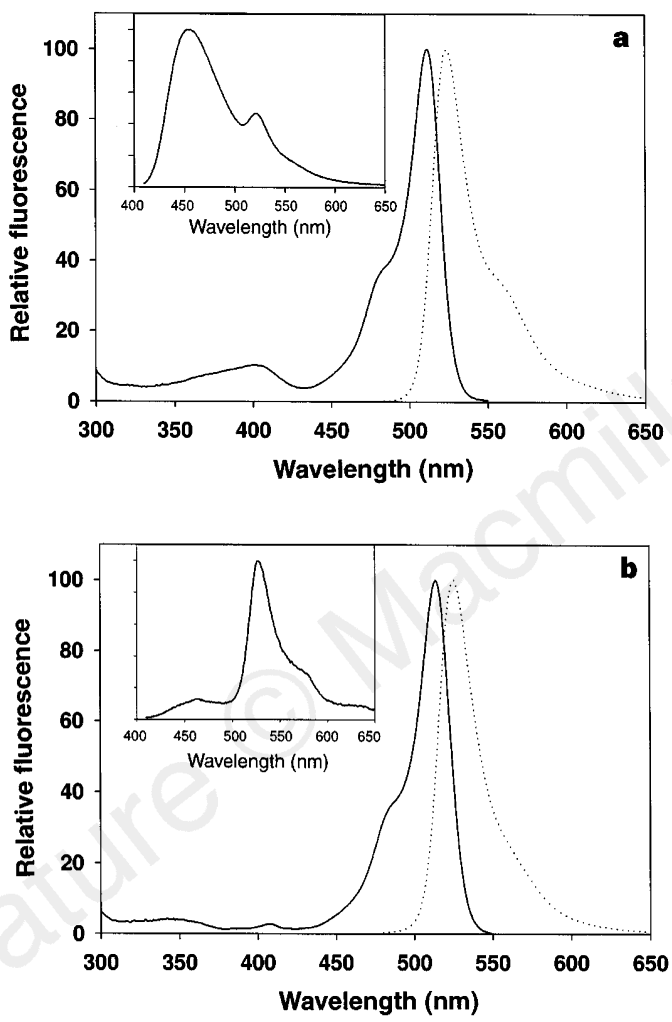

Figure 1 Bulk spectra of GFP mutants. a, T203F. Main figure: solid line, absorption; dotted line, emission excited by 488-nm irradiation. Inset, emission excited by 400-nm irradiation. b. T203Y. Main figure: solid line, absorption; dotted line, emission excited by $488-\mathrm{nm}$ irradiation. Inset, emission excited by $400-\mathrm{nm}$ irradiation. ments, is reminiscent of spectral and amplitude fluctuations reported previously for single small fluorophores ${ }^{9,10}$. These GFP mutants, however, show further interesting characteristics. Each GFP molecule generally ended in a non-fluorescent state after emission of $\sim 10^{6}$ photons. This final dark state was found to be long-lived: after $5 \mathrm{~min}$ with no pumping, the single molecules remained non-emissive on re-irradiation at $488 \mathrm{~nm}$ (Fig. 2, panels $1,3,5,7,9)$. The bright state could be reproducibly recovered, however, by irradiation at $405 \mathrm{~nm}$ for $5 \mathrm{~min}$ before 488 -nm reirradiation (Fig. 2, panels 2, 4, 6, 8, 10), an optically induced switching effect. To our knowledge, these GFP mutants provide the first example of a room-temperature optical switch in which each molecule is individually addressable, readout being accomplished quasi-non-destructively by way of fluorescence (similar to earlier liquid-helium-temperature systems $\mathrm{s}^{22}$ ). The bacteriorhodopsin protein also exhibits room-temperature switching, but it

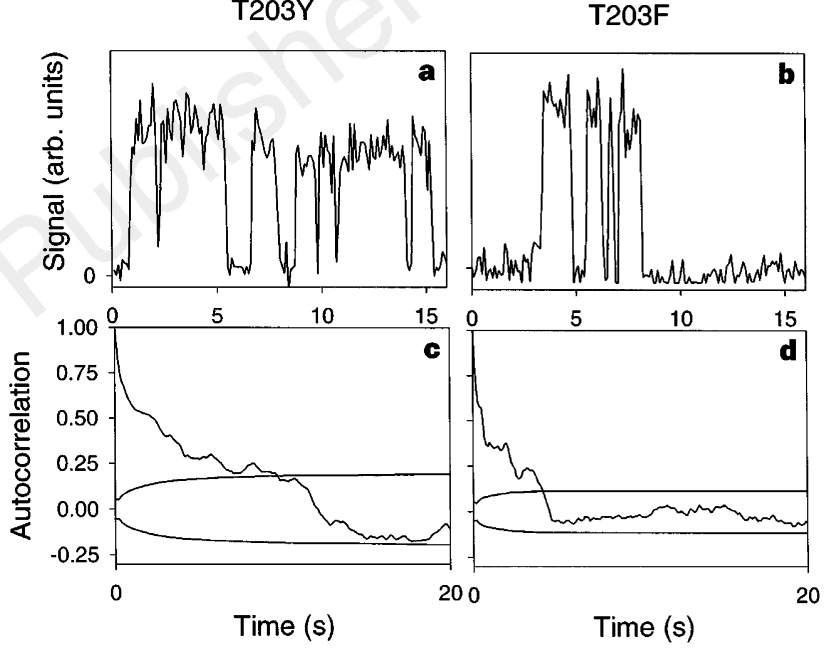

Figure 3 Traces of typical fluorescence intensity versus time for T203Y (a) and T203F (b) with an excitation intensity of $2,000 \mathrm{~W} \mathrm{~cm}^{-2}$. Each trace covers $16 \mathrm{~s}$. Autocorrelations of the fluorescence trajectories $\mathbf{a}$ and $\mathbf{b}$, expanded to illustrate the decay over the first 20 s, are shown in $\mathbf{c}$ and $\mathbf{d}$, respectively, with confidence limits.

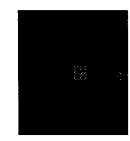

1

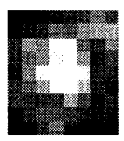

2

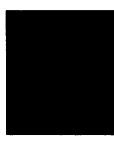

3

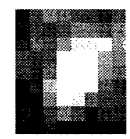

4

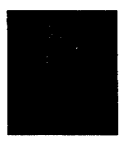

5

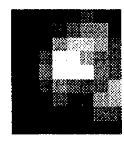

6

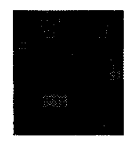

7

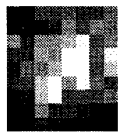

8

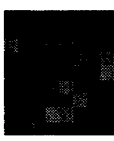

9

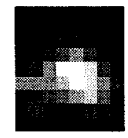

10

Figure 2 The switching behaviour of a single T203F molecule, illustrated by a series of ten consecutive experiments on the same molecule. Each 100-ms frame shows the emission produced by $488-\mathrm{nm}$ illumination $(60 \mathrm{~nm} \times 60 \mathrm{~nm}$ pixel size). In odd-numbered frames $(1,3,5,7,9)$, the sample was pre-illuminated for $90 \mathrm{~s}$ at $488 \mathrm{~nm}$ to prepare the long-lived dark state, followed by $5 \mathrm{~min}$ with no light incident, after which the displayed image was obtained. The dark state was still present in each case. In even-numbered frames $(2,4,6,8,10)$, the sample was also

pre-illuminated for $90 \mathrm{~s}$ at $488 \mathrm{~nm}$ to prepare the dark state, but then the sample was irradiated for $5 \mathrm{~min}$ at $405 \mathrm{~nm}\left(1 \mathrm{~W} \mathrm{~cm}^{-2}\right)$, after which the displayed image was immediately obtained. In each case, the emissive state is restored by the 405-nm irradiation. The odd-numbered cases assess the thermal stability of the dark state, whereas the even-numbered cases determine its photosensitivity to 405$\mathrm{nm}$ irradiation. Similar optical switching behaviour occurred for T203Y. 
efficiently photoisomerizes without fluorescing ${ }^{23}$, rendering it inaccessible to single-molecule detection and use.

Many single GFP molecule fluorescence trajectories (Fig. 3a, b) were analysed to develop on-time and off-time histograms commonly used in single-ion-channel recordings ${ }^{24}$. Only the highintensity data $\left(2,000 \mathrm{~W} \mathrm{~cm}^{-2}\right)$, however, produced a sufficient signal-to-noise ratio to reliably distinguish bright and dark by a single threshold. The on-time histograms were fitted by single exponentials (time constants: T203Y $0.86 \mathrm{~s}(n=89)$, T203F $0.71 \mathrm{~s}$ $(n=97))$. The dark-time histograms, however, showed bi-exponential decays for both mutants with a short decay time of $\sim 1 \mathrm{~s}$ and a long decay time greater than several tens of seconds (limited by our $90-\mathrm{s}$ data collection time), corresponding to the blinking and switching timescales, respectively.

To obtain more information from fluorescence trajectories at lower intensity, we use autocorrelation analysis, which has helped the understanding of several single-molecule systems ${ }^{14}$. Typical T203Y and T203F single-molecule autocorrelations are presented with confidence limits in Fig. $3 \mathrm{c}$, d. The autocorrelation time $\tau_{\mathrm{c}}$ (determined from an exponential fit to the autocorrelation decay) reflects the average period of on/off behaviour. Histograms of the $\tau_{\mathrm{c}}$ values from 377 individual GFP molecules are shown in Fig. 4 as a function of excitation intensity. Whereas the average autocorrelation time, $\tau_{\mathrm{c}}^{\mathrm{avg}}$, is reduced by only a factor of two for a 20 -fold increase in power, the single-molecule measurements produce the entire distribution, providing clear evidence that $\tau_{\mathrm{c}}$ shortens with increased intensity. As the autocorrelation measures how the fluorescence intensity correlates with itself in time, the faster and less power-dependent autocorrelation decays of $\mathrm{T} 203 \mathrm{Y}$ relative to those of T203F indicate that the additional hydroxyl group of T203Y facilitates a lower-energy pathway to chromophore activation/ inactivation (Fig 5).

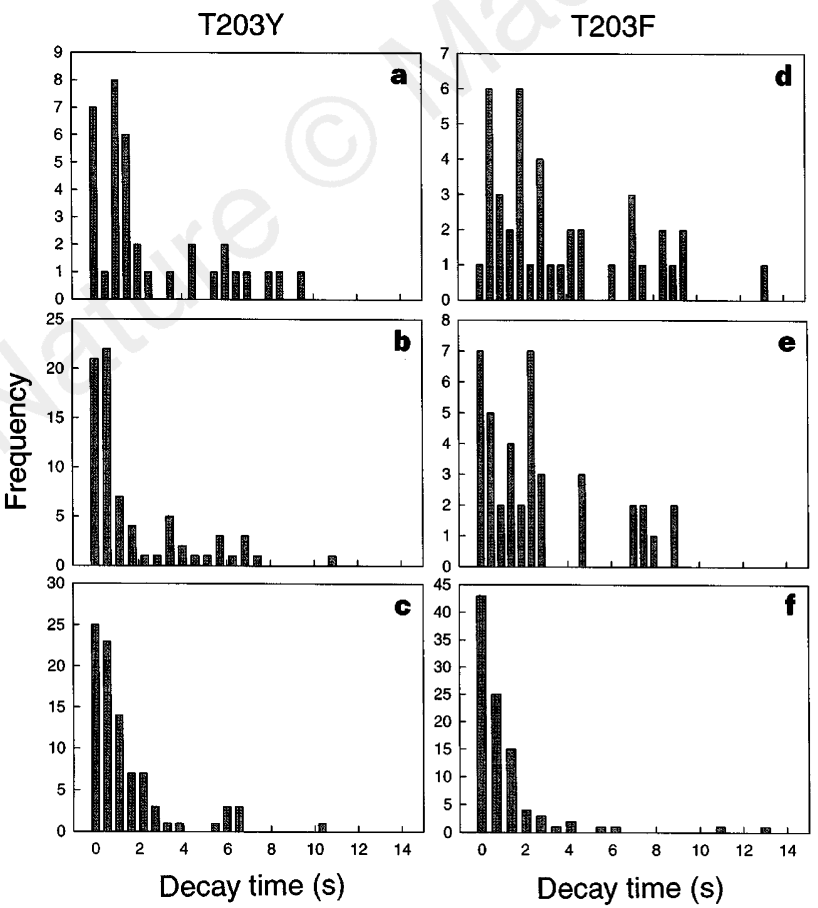

Figure 4 Histograms of single-molecule autocorrelation times $\tau_{\mathrm{c}}$ as a function of incident intensity; average autocorrelation times, $\tau_{\mathrm{c}}^{\text {avg }}$, are calculated from the distributions. Histograms a, b, c correspond respectively to T203Y at $100 \mathrm{~W} \mathrm{~cm}^{-2}$ $\left(\tau_{\mathrm{c}}^{\mathrm{avg}}=2.82 \pm 0.62 \mathrm{~s}, \quad n=36\right), \quad 500 \mathrm{~W} \mathrm{~cm}^{-2} \quad\left(\tau_{\mathrm{c}}^{\text {avg }}=2.01 \pm 0.36 \mathrm{~s}, \quad n=74\right)$ and $2,000 \mathrm{~W} \mathrm{~cm}^{-2}\left(\tau_{\circ}^{\mathrm{avg}}=1.61 \pm 0.27 \mathrm{~s}, n=89\right)$. Traces $\mathbf{d}$, e and $\mathbf{f}$ were generated from T203F data at respectively $100 \mathrm{~W} \mathrm{~cm}^{-2}\left(\tau_{\mathrm{c}}^{\text {avg }}=4.78 \pm 0.80 \mathrm{~s}, n=41\right)$, $500 \mathrm{~W} \mathrm{~cm}^{-2}\left(\tau_{\mathrm{c}}^{\text {avg }}=2.91 \pm 0.57 \mathrm{~s}, n=40\right)$ and $2,000 \mathrm{~W} \mathrm{~cm}^{-2}\left(\tau_{\mathrm{c}}^{\text {avg }}=1.37 \pm 0.27 \mathrm{~s}\right.$, $n=97)$. Quoted errors correspond to $80 \%$ confidence limits.

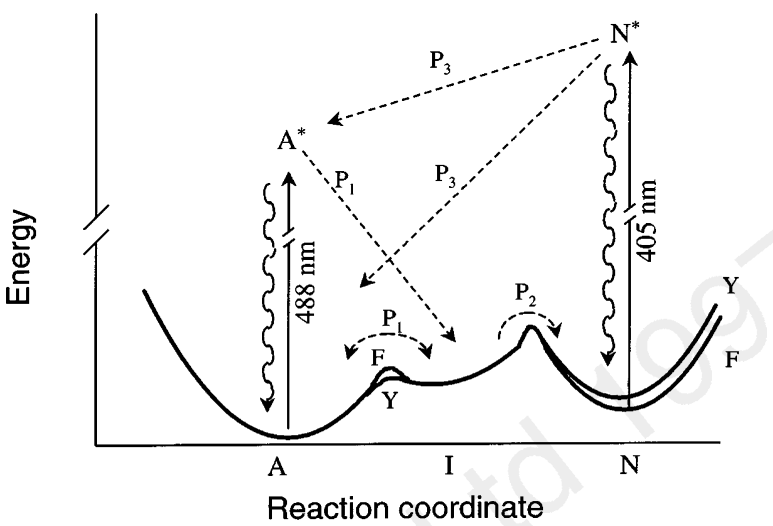

Figure 5 Schematic diagram of the various states consistent with the experimental observations as described in the text. For simplicity, the states are depicted as connected as $A \leftrightarrow I \leftrightarrow N$, but $I \leftrightarrow A \leftrightarrow N$ is also possible. $A^{*}$ and $N^{*}$ denote excited states of $A$ and $N$, respectively. See text for definitions of other symbols.

The observed single-molecule dynamics and bulk absorption and emission spectra suggest the model in Fig. 5. Because T203Y and T203F have strong absorption maxima near $513 \mathrm{~nm}$, we define the bright state as the anionic form, A, which absorbs 488-nm excitation and emits photons at $525 \mathrm{~nm}$, and the dark states as those which do not. The blinking indicates that a dark state, I, exists from which spontaneous return to A occurs, although the exact identity of form I is unknown at present. Processes $\mathrm{P}_{1}$ populate the state $\mathrm{I}$, either directly, or as a result of thermally activated barrier-crossing produced by cooling of excited vibrational levels of the electronic ground state. The latter possibility is consistent with the weak power dependences observed in the $\tau_{\mathrm{c}}$ values of both mutants (Fig. 4). In addition, there is another dark state which is eventually reached with lower probability (state $\mathrm{N}$, process $\mathrm{P}_{2}$ ) and which has a long lifetime ( $>5 \mathrm{~min}$ ) in the absence of light. We use " $\mathrm{N}$ " for this state as much evidence suggests this to be the neutral form ${ }^{15-18}$, and the data in Fig. 1a suggests that the less-polar solvation shell produced with Phe 203 favours this neutral state. The ground-state barriers in both mutants for the transition from state $\mathrm{N}$ to state I are large enough to allow ambient stability of state $\mathrm{N}$, consistent with the bi-exponential dark-time distributions. Excitation at $405 \mathrm{~nm}$, however, does regenerate state $\mathrm{A}$, by some third process $\mathrm{P}_{3}$, showing that light-induced conversion from the neutral to the anionic state occurs when higherenergy photons are present. Because the wild-type hydrogen-bonding and chromophore solvation shell are altered in T203Y and T203F, these mutants show distinct, but interconvertible, neutral and anionic states with very different photophysical properties.

These optical transformations of GFPs are likely to be obscured in ensemble-averaged measurements. Continuous monitoring of these immobilized single protein molecules shows that a process, which might be identified as irreversible 'bleaching', reverses on illumination at a different wavelength. This controllable photochromism may allow these GFP mutants to be used as caged fluorescent markers to monitor time-dependent cellular processes such as protein diffusion or transport ${ }^{25}$. Photochromic GFPs could also offer potential advantages in optical information storage ${ }^{26,27}$ such as high storage densities ( 1 bit per molecule), photostability even in aereated samples, fluorescent readout, ease of production, known atomic resolution structure, and amenability to optimization by mutagenesis.

\section{Methods}

Mutants. GFP was expressed in Escherichia coli using the expression plasmid pRSET (Invitrogen) in which the region encoding GFP was fused in-frame with 
nucleotides encoding an amino-terminal polyhistidine tag. Sequence changes were introduced by site-directed mutagenesis using the Bio-Rad mutagenesis $\mathrm{kit}^{28}$ and confirmed by sequencing. The recombinant proteins were expressed in the bacterial strain BL21(DE3) after induction with IPTG $(0.5 \mathrm{mM})$ at room temperature and purified by $\mathrm{Ni}$ affinity chromatography.

T203F/T203Y imaging. Samples were prepared by the methods of ref. 21 from $10^{-10} \mathrm{M}$ solutions of protein diluted in $1 \mathrm{mg} \mathrm{ml}^{-1}$ BSA. Polyacrylamide gels ( $T=15 \%, C=5 \%$ without SDS) were prepared in $\mathrm{pH} 7$ phosphatebuffered saline doped with protein (here $T$ is the total concentration of monomer in g per $100 \mathrm{ml}, C$ is the wt $\%$ of total monomer which is crosslinker, and SDS indicates sodium dodecyl sulphate). The gel host provided pore sizes small enough for convenient (and complete) immobilization of each protein molecule, while maintaining its naturally fluorescent, native conformation ${ }^{21,29}$. Excitation with a $488-\mathrm{nm}$ laser $\left(100-2,000 \mathrm{~W} \mathrm{~cm}^{-2}\right.$ at the gel/coverslip interface) occurred in the total-internal-reflection geometry; the emission was imaged with a Nikon inverted microscope (250-nm resolution) with an Omega 535DF55 filter and a Princeton Instruments intensified frame transfer CCD (100 ms time resolution, $90 \mathrm{~s}$ collection time). Oxygen was not removed from samples for which data is shown, but samples prepared with $\sim 10 \mathrm{~min}$ helium bubbling showed similar on/off behaviour. 405-nm irradiation was produced by a $\mathrm{Hg}$ arc lamp with line filter through the epi-illumination port $\left(1 \mathrm{~W} \mathrm{~cm}^{-2}\right)$. The linear increase of detected photons as a function of laser intensity $\left(100-2,000 \mathrm{~W} \mathrm{~cm}^{-2}\right)$ indicated that saturation and multiphoton processes were negligible in these studies. Typical detected count rates of $5,000-6,000$ photons $\mathrm{s}^{-1}$ at $2,000 \mathrm{~W} \mathrm{~cm}^{-2}$ pumping intensity $(\sim 150,000$ excitations s$^{-1}$ ) were achieved, with most of the molecules emitting several millions of photons without irreversible bleaching.

Autocorrelation analysis. We define the autocorrelation function, $C(\tau)$, for discrete data points;

$$
C(\tau)=\sum_{t=0}^{N}(I(t)-\bar{I})(I(t+\tau)-\bar{I}) / \sum_{t=0}^{N}(I(t)-\bar{I})^{2}
$$

where $\bar{I}$ is the average intensity, $t$ is the time summed from 0 to $N 100$-ms intervals, and $I(t)$ is the time-dependent fluorescence intensity. Confidence limits were generated on the autocorrelations such that any values within the limits were consistent with zero ${ }^{30}$. Exponential fits of the autocorrelations were generated only for the statistically significant portions of the curves beyond the short time correlation spike arising from band-limited noise.

Received 8 April; accepted 17 June 1997

1. Moerner, W. E. \& Kador, L. Optical detection and spectroscopy of single molecules in a solid. Phys, Rev. Lett. 62, 2535-2538 (1989).

2. Orrit, M. \& Bernard, J. Single pentacene molecules detected by fluorescence excitation in a pterphenyl crystal. Phys. Rev. Lett. 65, 2716-2719 (1990).

Reilly, P. D. \& Skinner, J. L. Spectral diffusion of single molecule fluorescence: a probe of lowfrequency localized excitations in disordered crystals. Phys. Rev. Lett. 71, 4257-4260 (1993).

4. Moerner, W. E. Examining nanoenvironments in solids on the scale of a single, isolated molecule. Science 265, 46-53 (1994).

5. Barbara, P. F. \& Moerner, W. E. (eds) Single molecules and atoms. Acc. Chem. Res. 29, (1996).

6. Betzig, E. \& Chichester, R. J. Single molecules observed by near-field scanning optical microscopy. Science 262, 1422-1428 (1993)

7. Ambrose, W. P., Goodwin, P. M., Martin, J. C. \& Keller, R. A. Alterations of single molecule fluorescence lifetimes in near-field optical microscopy. Science 265, 364-367 (1994).

8. Nie, S., Chiu, D. T. \& Zare, R. N. Probing individual molecules with confocal fluorescence microscopy. Science 266, 1018-1021 (1994).

9. Trautman, J. K. \& Macklin, J. J. Time-resolved spectroscopy of single molecules using near-field and far-field optics. Chem. Phys. 205, 221-229 (1996).

10. Lu, H. P. \& Xie, X. S. Single-molecule spectral fluctuations at room temperature. Nature 385, 143-146 (1997).

11. Funatsu, T., Harada, Y., Tokunaga, M., Saito, K. \& Yanagida, T. Imaging of single fluorescent molecules and individual ATP turnovers by single myosin molecules in aqueous solution. Nature 374, 555-559 (1995).

12. Vale, R. D. et al. Direct observation of single kinesin molecules moving along microtubules. Nature 380, 451-453 (1996).

13. Schmidt, T., Schutz, G. J., Baumgartner, W., Gruber, H. J. \& Schindler, H. Imaging of single molecule diffusion. Proc. Natl Acad. Sci. USA 93, 2926-2929 (1996).

14. Basché, T., Moerner, W. E., Orrit, M. \& Wild, U. P. (eds) Single Molecule Optical Detection, Imaging, and Spectroscopy (Verlag-Chemie, Munich, 1997).

15. Heim, R., Prasher, D. C. \& Tsien, R. Y. Wavelength mutations and posttranslational autoxidation of green fluorescent protein. Proc. Natl Acad. Sci. USA 91, 12501-12504 (1994).

16. Cubitt, A. B. et al. Understanding, improving and using green fluorescent proteins. Trends Biochem Sci. 20, 448-455 (1995).

17. Chattoraj, M., King, B. A., Bublitz, G. U. \& Boxer, S. G. Ultra-fast excited state dynamics in green fluorescent protein: Multiple states and protein transfer. Proc. Natl Acad. Sci USA 93, 8362-8367 (1996).

18. Brejc, K. et al. Structural basis for dual excitation and photoisomerization of the Aequorea victoria green fluorescent protein. Proc. Natl. Acad. USA 94, 2306-2322 (1997).

19. Ormo, M. et al. Crystal structure of the Aequorea victoria green fluorescent protein. Science 273, 1392 1395 (1996).
20. Yang, F., Moss, L. G. \& Phillips, J. G. N. The molecular structure of green fluorescent protein. Nature Biotechnol. 14, 1246-1251 (1996).

21. Dickson, R. M., Norris, D. J., Tzeng, Y.-L. \& Moerner, W. E. Three dimensional imaging of single molecules in pores of poly(acrylamide) gels. Science 274, 966-969 (1996).

22. Moerner, W. E. et al. Optical probing of single molecules of terrylene in a Shpolskii matrix-a twostate single-molecule switch. J. Phys. Chem. 98, 7382-7389 (1994).

23. Stuart, J. A., Tallent, J. R., Tan, E. H. L. \& Birge, R. R. in Sixth Biennial IEEE Intl Nonvolatile Memory Technol. Conf. Proc. 35-51 (IEEE, Albuquerque, NM, 1996).

24. Sakmann, B. \& Neher, E. Single Channel Recording (Plenum, New York, 1995).

25. Yokoe, H. \& Meyer, T. Spatial dynamics of GFP-tagged proteins investigated by local fluorescence enhancement. Nature Biotechnol. 14, 1252-1256 (1996).

26. Irie, M. in Photo-reactive Materials for Ultrahigh Density Optical Memory (ed. Irie, M.) 1-12 (Elsevier Science, Amsterdam, 1994).

27. Parthenopoulos, D. A. \& Rentzepis, P. M. Three-dimensional optical storage memory. Science $\mathbf{2 4 5}$, 843-845 (1989).

28. Kunkel, T. A., Roberts, J. D. \& Zakour, R. A. Rapid and efficient site-specific mutagenesis without phenotypic selection. Meth. Enzymol. 154, 367-382 (1987).

29. Fawcett, J. S. \& Morris, C. J. O. R. Molecular-sieve chromatography of proteins on granulated polyacrylamide gels. Separat. Sci. 1, 9-26 (1966).

30. Box, G. E. P. \& Jenkins, G. M. Time Series Analysis Forecasting and Control (Holden-Day, San Francisco, 1970)

Acknowledgements. We thank L. S. B. Goldstein and S. Kummer for discussions. This work was supported by the NSF.

Correspondence and requests for materials should be addressed to W.E.M. (e-mail:wmoerner@ucsd.edu).

\section{The soil production function and landscape equilibrium}

\section{Arjun M. Heimsath ${ }^{\star}$, William E. Dietrich* Kunihiko Nishiizumi $\uparrow$ \& Robert C. Finkel $\ddagger$}

* Department of Geology and Geophysics, 301 McCone Hall, University of California, Berkeley, California 94720-4767, USA

$\dagger$ Space Sciences Laboratory, University of California, Berkeley, California 94720-7450, USA

$\$$ Center for Accelerator Mass Spectrometry, Lawrence Livermore National Laboratory, Livermore, California 94550, USA

Hilly and mountainous landscapes are partially to completely covered with soil under a wide range of erosion and uplift rates, bedrock type and climate. For soil to persist it must be replenished at a rate equal to or greater than that of erosion. Although it has been assumed for over 100 years that bedrock disintegration into erodable soil declines with increasing soil mantle thickness ${ }^{1-9}$, no field data have shown this relationship. Here we apply two independent field methods for determining soil production rates to hillslopes in northern California. First, we show that hillslope curvature (a surrogate for soil production ${ }^{7}$ ) varies inversely with soil depth. Second, we calculate an exponential decline of soil production rates with increasing soil depth from measurements of the in situ produced cosmogenic ${ }^{10} \mathrm{Be}$ and ${ }^{26} \mathrm{Al}$ concentrations in bedrock sampled under soils of different depths. Results from both methods agree well and yield the first empirical soil production function. We also illustrate how our methods can determine whether a landscape is in morphological equilibrium or not.

Soil thickness depends on the balance between production and erosion of soil (Fig. 1). We define soil to be distinct colluvial material, lacking relict rock structure and derived from underlying bedrock. The mechanical disruption that destroys rock structure and lowers the soil-bedrock interface may be due to processes that are biotic (for example, burrowing and three throw) ${ }^{7}$ or abiotic (for example, dissolution-induced collapse, freeze-thaw, and shear deformation). Downslope soil transport can occur by mass wasting, overland flow, and biogenic disturbance. We focus on diffusive transport where the sediment flux, $\tilde{q}_{\mathrm{s}}$, is proportional to slope, $\nabla z$, such that $\tilde{q}_{\mathrm{s}}=-K \nabla z$; here $K$ is equivalent to a diffusion coefficient with dimensions (length) $)^{2}$ (time) ${ }^{-1}$. This relationship was articulated by Davis ${ }^{10}$ and Gilbert ${ }^{11}$ and has been extensively applied in 